\title{
Stillbirth should be given greater priority on the global health agenda
}

Stillbirths are largely excluded from international measures of mortality and morbidity. Zeshan Qureshi and colleagues argue that stillbirth should be higher on the global health agenda.

\section{Zeshan U Qureshi academic clinical fellow in international child health ${ }^{1}$, Joseph Millum bioethicist ${ }^{2}$, Hannah Blencowe lecturer in infectious disease epidemiology ${ }^{3}$, Maureen Kelley associate professor in bioethics ${ }^{4}$, Edward Fottrell lecturer in epidemiology and global health metrics ${ }^{1}$, Joy E Lawn professor in maternal, reproductive, and child health epidemiology ${ }^{3}$, Anthony Costello professor in international child health ${ }^{1}$, Tim Colbourn lecturer in global health epidemiology and evaluation ${ }^{1}$}

${ }^{1}$ Institute for Global Health, University College London, London, UK; ${ }^{2}$ Clinical Center Department of Bioethics/Fogarty International Center, National Institutes of Health, Bethesda, USA; ${ }^{3}$ Maternal, Adolescent, Reproductive, and Child Health Centre, London School of Hygiene and Tropical Medicine, London, UK; ${ }^{4}$ Ethox Centre, Nuffield Department of Population Health, Oxford University, Oxford, UK

\begin{abstract}
The global rate of stillbirths was estimated to be 18.9 per 1000 births in 2009 , equating to a total of 2.64 million stillbirths, 1.2 million of which were during labour. ${ }^{1-3}$ The burden is heaviest for women in low and middle income countries and the poorest women in high income countries. ${ }^{2}$ Given its scale, stillbirth prevention should be high on the global health agenda. However, in the current draft of the United Nations sustainable development goals, which sets global targets for 2015-30, stillbirth is not mentioned, even though neonatal and under 5 mortality rates are included. ${ }^{4}$

Explicit targets and accountability to track and reduce national stillbirth rates would help raise the political profile of stillbirths, engaging global leaders and increasing country government programmatic action. The Every Newborn action plan, which aims to provide all nations with a platform for ending preventable newborn deaths and stillbirths, proposed a target of reducing the stillbirth rate to $\leq 12$ per 1000 births in every country by $2030 .^{3}$ There is a strong case to be made at country and international levels that the introduction of stillbirth targets will encourage greater investment in perinatal care interventions. This has the potential to reduce neonatal and maternal deaths, as well as stillbirths, giving a triple return on programme investment and research.

In this article we argue for international adoption of the Every Newborn action plan stillbirth targets.
\end{abstract}

\section{Definition}

To facilitate international comparisons and improve measurement, the World Health Organization recommends a definition of stillbirth as late fetal loss with a birth weight of $\geq 1000$ g or length $\geq 35 \mathrm{~cm}$, or after 28 weeks. Many high income countries report stillbirths using additional definitions. For example, there is a cut-off of 24 weeks in the United Kingdom, 20 weeks (or $400 \mathrm{~g}$ ) in Australia, and state variations in the United States. ${ }^{2}$ For this article, we use the international WHO definition because it is the only one with national and global estimates. ${ }^{2}$ If the definitions used in high income countries were applied, the international incidence of stillbirth would be even greater.

\section{Burden and global health metrics}

Rates of stillbirth were not mentioned in the UN millennium development goals, have not been counted in the Global Burden of Disease study, and are not routinely reported to WHO, even though the data are collected by some countries with vital registration and other systems. ${ }^{26}$ The first national estimates of stillbirth rates to be published were for the year 2000, and the first WHO national estimates were for the year 2009. ${ }^{17}$ For high income countries the data are substantial with narrow uncertainty, but for south Asia and sub-Saharan Africa, which have two thirds of the total global burden, the estimation uncertainty is wide. ${ }^{2}$

In many low and middle income countries women may become pregnant and have a stillbirth without coming into contact with a healthcare professional. Thus most stillbirths are not officially recorded. ${ }^{2}$ National registration systems of all births, stillbirths, and other deaths are needed in every country. They are receiving more investment but will take time to reach scale in the poorest communities. ${ }^{3}$ This is a major challenge, particularly in remote 
settings. In the interim other large scale data platforms, such as the District Health Information System, have started to count stillbirths. Household surveys such as the Demographic and Health Surveys also report stillbirths, but the quality of data has been questioned owing to recall bias, the difficulty of distinguishing between stillbirths and early neonatal deaths, and sensitivities around oral autopsies.

The millennium development goals demonstrated that governments and donors are more likely to invest in programmes and tracking for outcomes that they have to account for publicly. ${ }^{8}$ Unlike stillbirth, there has been a strong national and international political drive to improve maternal and child health. Between 1995 and 2009 the global rate of stillbirths decreased by around $1 \%$ a year compared with around $5 \%$ a year for postneonatal child survival rate. ${ }^{1}$ The availability and quality of data for child mortality have risen dramatically. National child mortality estimates are now published annually by the UN Inter-agency Group for Child Mortality Estimation and the Institute for Health Metrics and Evaluation, with substantial media attention. ${ }^{9}$ Leaving stillbirths out of the sustainable development goals is likely to leave them still uncounted. ${ }^{2}$

\section{Stillbirths and neonatal deaths should have similar value}

Economic evaluations of interventions to improve maternal and child health do not routinely include the prevention of stillbirth in measurements of life years gained, disability adjusted life years averted, or quality adjusted life years gained. However, there are ethical and pragmatic reasons to give similar value to stillbirths and neonatal deaths. Some philosophers argue that the development of capacities such as sentience and self awareness are fundamental to moral consideration. ${ }^{10}{ }^{11}$ Given the similarity in cognitive development between late term fetuses and newborns, the death of both should be considered similarly in terms of harm and loss. ${ }^{12}$ The death of a 23 week preterm baby on the first day of life will be registered as a neonatal death and counted in national statistics and accountability frameworks, whereas a 41 week baby that dies during labour, despite being 18 weeks more mature, is labelled as a stillbirth, and risks remaining uncounted.

Moreover, the 23 week neonate has limited potential for a healthy life, even with substantial tertiary neonatal care, whereas most of the annual 1.2 million intrapartum stillbirths could be prevented with a modest investment in intrapartum care. ${ }^{5}$

\section{Women's reproductive rights and impact on families}

Efforts to protect and fulfil women's reproductive rights have often focused on women's rights to safe abortion. ${ }^{13}$ However, women's reproductive rights also encompass supporting wanted pregnancies, minimising harm to mother and baby during pregnancy and childbirth, and ensuring survival and care of newborns. Many wanted pregnancies end in stillbirth, and the psychological effects on parents can last a lifetime. ${ }^{14}{ }^{15}$ Parents report depression and anxiety after a stillbirth, as well as psychological difficulties in subsequent pregnancies. ${ }^{16}$ Psychological distress may require counselling or medical treatment, with some parents experiencing long term post-traumatic stress disorder. ${ }^{14}{ }^{17}{ }^{18}$ Studies in high income countries and in low and middle income countries have found that parents' grief is often not socially recognised nor fully acknowledged by doctors or society. ${ }^{17}{ }^{19}$ Many parents value holding, bathing, and photographing their deceased baby. ${ }^{20}$
For some parents the relationship continues, including activities such as conversation with the deceased child and rituals to remember the baby. ${ }^{20}$

Women also face physical health consequences. In low and middle income countries pregnancy is associated with substantial mortality and morbidity, particularly during labour and in the early postnatal period. ${ }^{22}$ Stillbirth exacerbates this risk. ${ }^{23}$ For example, obstructed labour, common in low and middle income countries without access to good emergency obstetric care, is a cause of stillbirth and obstetric fistula. ${ }^{24}$ Stillbirth is also associated with short intervals between pregnancies. ${ }^{25} \mathrm{~A}$ data linkage study in England and Scotland found that women who had experienced a stillbirth or death of a child before the age of 1 were more likely to die in the first 15 years after the loss than the non-bereaved. This association remained significant at 35 year follow-up. ${ }^{26}$

\section{Challenges and potential conflicts}

Advocates for women's reproductive rights have voiced concerns about whether a greater emphasis on stillbirth prevention would conflict with women's reproductive rights. ${ }^{27}$ Recognising stillbirths as equivalent to neonatal deaths raises questions about the moral status of all late term fetuses. Would this increase the profile of fetal rights and potentially impinge on the right to an abortion? The estimated 21.6 million unsafe abortions performed each year are a preventable cause of maternal morbidity and result in an estimated 47000 maternal deaths a year. Most (98\%) occur in low and middle income countries where abortion is usually illegal and is performed under unsafe conditions and where family planning services are also often lacking. ${ }^{28}$ However, almost all abortions occur well before 28 weeks, so do not fall under the WHO definition of stillbirth. In the UK, for example, $79 \%$ of abortions occur within the first 10 weeks of gestation, and less than $0.1 \%$ take place after 24 weeks. ${ }^{29}$ There is widespread ethical agreement that third trimester fetuses should have some protection from intentional termination. ${ }^{27}$ Even if late term abortion were considered a negative health outcome, the appropriate policy response would not necessarily be to limit access to late term abortions. It would more likely favour increasing the provision of family planning services and access to earlier abortions.

There are other challenges to stillbirths being "counted." Vital registration often relies on families registering the stillbirth themselves. Some communities associate stillbirth with maternal fault - for example, as an expression of her destiny, possession by evil spirits, or a punishment for previous sins. ${ }^{30}$ This may lead to stigma and marginalisation of the mother after reporting a stillbirth. Direct costs associated with registering a stillbirth include travel and lost productivity. In addition, distinguishing between stillbirth, miscarriage, and neonatal death may be difficult in settings where there have been no antenatal scans, the baby has never been weighed, and no healthcare professional has assessed the baby. ${ }^{30} 31$

Understanding such challenges is important for the design and implementation of routine systems to actively record stillbirths. Approaches used effectively in large scale population research may be good models for this. ${ }^{32}$ Recent advances in verbal autopsy tools offer ways to distinguish between early neonatal deaths and stillbirths. ${ }^{33}$ WHO led initiatives in this field have focused on simplifying data collection and analysis processes so that mortality surveillance, including stillbirths, is more easily implemented on a large scale routine basis in low and middle income countries. ${ }^{34}$ Using such methods to add stillbirths to countries' existing mortality monitoring and reporting 
responsibilities need not be at the expense of other mortality indicators.

Another possible concern about investing in preventing stillbirths and child deaths is that it might accelerate population growth. However, reducing child mortality is crucial to reducing fertility rates and consequent population growth. When parents believe their children are more likely to survive they tend to have fewer children. ${ }^{35-37}$ The same rationale is likely to apply to stillbirth prevention. In any case, the idea that we should address overpopulation by allowing preventable stillbirths and newborn deaths seems unethical.

\section{Interventions}

If stillbirth does gain a greater political profile, investment needs to be directed towards evidence based interventions that can successfully reduce stillbirth rates. Inclusion of stillbirths in economic evaluations of pregnancy and childbirth interventions increases their cost effectiveness. ${ }^{58}{ }^{39}$ A systematic review of interventions against preventable perinatal deaths estimated that 531000 stillbirths, 113000 maternal deaths, and 1.325 million neonatal deaths could realistically be averted every year until 2020 for $\$ 4.5 \mathrm{bn}(£ 2.9 \mathrm{bn} ; € 4.0 \mathrm{bn})$ a year or $\$ 0.90$ per capita in the 75 highest burden countries. ${ }^{40}$ The focus of interventions depends on the setting. In low and middle income countries, where $98 \%$ of stillbirths occur, intrapartum stillbirths make up a higher percentage of the total stillbirth population (fig $1 \Downarrow$ ).

Most of these stillbirths, particularly those that are intrapartum, are entirely preventable with known, effective interventions, including high quality basic antenatal care and care during labour (box). Advanced antenatal care, including fetal growth monitoring and accurate pregnancy dating with induction of post-term infants, is likely to be more relevant in middle and high income settings.

\section{Conclusions}

Collection of data about stillbirths and their prevention has low priority in global policy. Countries are directly accountable for their maternal and neonatal mortality rates but not stillbirth rates. Women's reproductive health and rights are central to this debate. Raising the profile of stillbirth would enhance women's reproductive rights, not reduce them. Counting stillbirths in health metrics and economic evaluations is long overdue. Without accelerated action, an additional 52 million stillbirths will occur between now and $2035 .{ }^{3}$ Having a specific stillbirth related target in the sustainable development goals could bring attention to this silent loss and halve this burden.

Contributors and sources: The authors bring a combination of expertise in epidemiology, economic evaluation, interventions, ethics, and advocacy. ZUQ wrote the first draft of the manuscript. TC, JM, JEL, HB, $\mathrm{MK}, \mathrm{EF}$, and $\mathrm{AC}$ contributed intellectual content and critical revisions to the manuscript. All authors approved the final manuscript. ZUQ is guarantor.

Competing interests: We have read and understood BMJ policy on declaration of interests and have no relevant interests to declare.

The views expressed are the authors' own. They do not represent the position or policy of the National Institutes of Health, US Public Health Service, or the Department of Health and Human Services.

1 Cousens S, Blencowe H, Stanton C, et al. National, regional, and worldwide estimates of stillbirth rates in 2009 with trends since 1995: a systematic analysis. Lancet 2011;377:1319-30
2 Lawn JE, Blencowe H, Pattinson R, et al. Stillbirths: Where? When? Why? How to make the data count? Lancet 2011;377:1448-63.

3 Lawn JE, Blencowe H, Oza S, et al. Every Newborn: progress, priorities, and potential beyond survival. Lancet 2014;384:189-205

4 United Nations. Open working group proposal for sustainable development goals. https: //sustainabledevelopment.un.org/focussdgs.html.

5 Pattinson R, Kerber K, Buchmann E, et al. Stillbirths: how can health systems deliver for mothers and babies? Lancet 2011;377:1610-23

6 Lozano R, Naghavi M, Foreman K, et al. Global and regional mortality from 235 causes of death for 20 age groups in 1990 and 2010: a systematic analysis for the Global Burden of Disease Study 2010. Lancet 2012;380:2095-128.

7 Stanton C, Lawn JE, Rahman H, Wilczynska-Ketende K, Hill K. Stillbirth rates: delivering estimates in 190 countries. Lancet 2006;367:1487-94.

8 Darmstadt GL, Kinney MV, Chopra M, et al. Who has been caring for the baby? Lancet 2014;384:174-88.

9 Unicef. Levels and trends in Child Mortality. Report 2014. www.unicef.org/media/files/ Levels_and_Trends_in_Child_Mortality_2014.pdf.

10 Tooley M. Abortion and infanticide. Oxford University Press, 1983.

11 Sumner L. Abortion and moral theory. Princeton University Press, 1981.

12 Phillips J, Millum J. Valuing stillbirths. Bioethics 2014:29:413-23.

13 Grimes DA, Benson J, Singh S, et al. Unsafe abortion: the preventable pandemic. Lancet 2006;368:1908-19

14 Badenhorst W, Riches S, Turton P, Hughes P. The psychological effects of stillbirth and neonatal death on fathers: systematic review. J Psychosom Obstet Gynaecol 2006;27:245-56.

15 Scott J. Stillbirths: breaking the silence of a hidden grief. Lancet 2011;377:1386-8.

16 Hughes PM, Turton P, Evans CD. Stillbirth as risk factor for depression and anxiety in the subsequent pregnancy: cohort study. BMJ 1999;318:1721-4.

17 Kelley MC, Trinidad SB. Silent loss and the clinical encounter: Parents' and physicians' experiences of stillbirth-a qualitative analysis. BMC Pregnancy and Childbirth 2012;12:137.

18 Turton P, Hughes P, Evans CD, Fainman D. Incidence, correlates and predictors of post-traumatic stress disorder in the pregnancy after stillbirth. Br J Psychiatry 2001;178:556-60.

19 Hamid S, Malik AU, Richard F. Stillbirth-a neglected priority: understanding its social meaning in Pakistan. J Pak Med Assoc 2014;64:331-3.

20 Bonnette S, Broom A. On grief, fathering and the male role in men's accounts of stillbirth. J Sociol 2012;48:248-265.

21 Cacciatore J, Rảdestad I, Frederik Frøen J. Effects of contact with stillborn babies on maternal anxiety and depression. Birth 2008;35:313-20.

22 Kassebaum NJ, Bertozzi-Villa A, Coggeshall MS, et al. Global, regional, and national levels and causes of maternal mortality during 1990-2013: a systematic analysis for the Global Burden of Disease Study 2013. Lancet 2014;384:980-1004.

23 Høj L, da Silva D, Hedegaard K, Sandström A, Aaby P. Factors associated with maternal mortality in rural Guinea-Bissau. A longitudinal population-based study. BJOG 2002;109:792-9.

24 Dolea CAC. Global burden of obstructed labour in the year 2000. Geneva, 2003

25 Conde-Agudelo A, Belizán JM, Norton MH, Rosas-Bermúdez A. Effect of the interpregnancy interval on perinatal outcomes in Latin America. Obstet Gynecol 2005;106:359-66.

26 Harper M, O'Connor RC, O'Carroll RE. Increased mortality in parents bereaved in the first year of their child's life. BMJ Support Palliat Care 2011:1:306-9.

27 Kelley M. Counting stillbirths: women's health and reproductive rights. Lancet 2011;377:1636-7.

28 WHO. Unsafe abortion incidence and mortality. Global and regional levels in 2008 and trends during 1990-2008. 2012. http://apps.who.int/iris/bitstream/10665/75173/1/WHO RHR 12.01_eng.pdf.

29 Department of Health. Abortion statistics, England and Wales: 2013. Jun 2014. www.gov. uk/government/uploads/system/uploads/attachment_data/file/319460/Abortion_Statistics_ England_and_Wales_2013.pdf.

30 Frøen JF, Cacciatore J, McClure EM, et al. Stillbirths: why they matter. Lance 2011;377:1353-66

31 Goldenberg RL, McClure EM, Jobe AH, Kamath-Rayne BD, Gravette MG, Rubens CE. Stillbirths and neonatal mortality as outcomes. Int J Gynaecol and Obstet 2013:123:252-3.

32 Bapat U, Alcock G, More NS, Das S, Joshi W, Osrin D. Stillbirths and newborn deaths in slum settlements in Mumbai, India: a prospective verbal autopsy study. BMC Pregnancy Childbirth 2012;12:39.

33 Vergnano S, Fottrell E, Osrin D, et al. Adaptation of a probabilistic method (InterVA) of verbal autopsy to improve the interpretation of cause of stillbirth and neonatal death in Malawi, Nepal, and Zimbabwe. Popul Health Metr 2011:9:48.

34 Leitao J, Chandramohan D, Byass P, et al. Revising the WHO verbal autopsy instrument to facilitate routine cause-of-death monitoring. Glob Health Action 2013;6:21518.

35 Lithell UB, Rosling H, Hofvander Y. Children's deaths and population growth. Lancet 1992;339:377-8.

36 Hossain MB, Phillips JF, Legrand TK. The impact of childhood mortality on fertility in six rural thanas of Bangladesh. Demography 2007:44:771-84.

37 Stenberg K, Axelson $\mathrm{H}$, Sheehan $\mathrm{P}$, et al. Advancing social and economic development by investing in women's and children's health: a new global investment framework. Lancet 2014;383:1333-54

38 Simon J, Petrou S, Gray A. The valuation of prenatal life in economic evaluations of perinatal interventions. Health Econ 2009;18:487-94.

39 Colbourn T, Pulkki-Brännström AM, Nambiar B, et al. Cost-effectiveness and affordability of community mobilisation through women's groups and quality improvement in health facilities (MaiKhanda trial) in Malawi. Cost Eff Resour Alloc 2015;13:1.

40 Bhutta ZA, Das JK, Bahl R, et al. Can available interventions end preventable deaths in mothers, newborn babies, and stillbirths, and at what cost? Lancet 2014;384:347-70.

Accepted: 22 July 2015

Cite this as: BMJ 2015;351:h4620

(c) BMJ Publishing Group Ltd 2015 


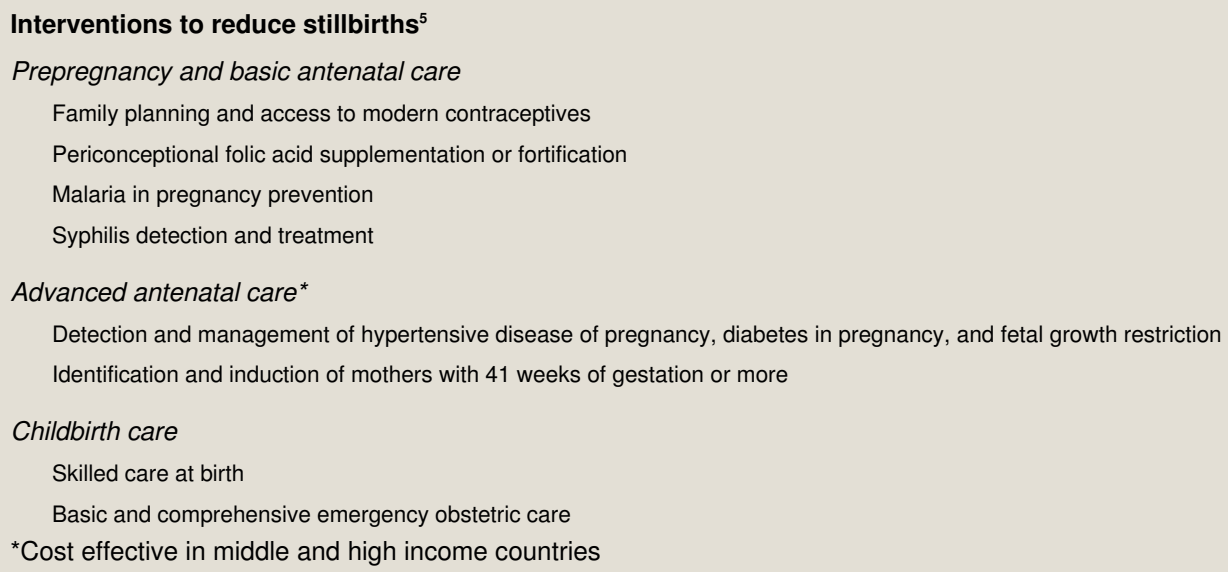

\section{Key messages}

Stillbirths are largely excluded from international measures of mortality and morbidity and were not mentioned in the millennium development goals

Stillbirth rates have fallen much more slowly than maternal and child death rates, which do have specific millennium development goal targets

Stillbirths should be included in routine national and global health metrics and in economic evaluations of the cost effectiveness of options for health spending

Without clear national targets for prevention of stillbirths in the post-2015 development framework, there will continue to be little incentive to invest in interventions or in better stillbirth data

\section{Figure}

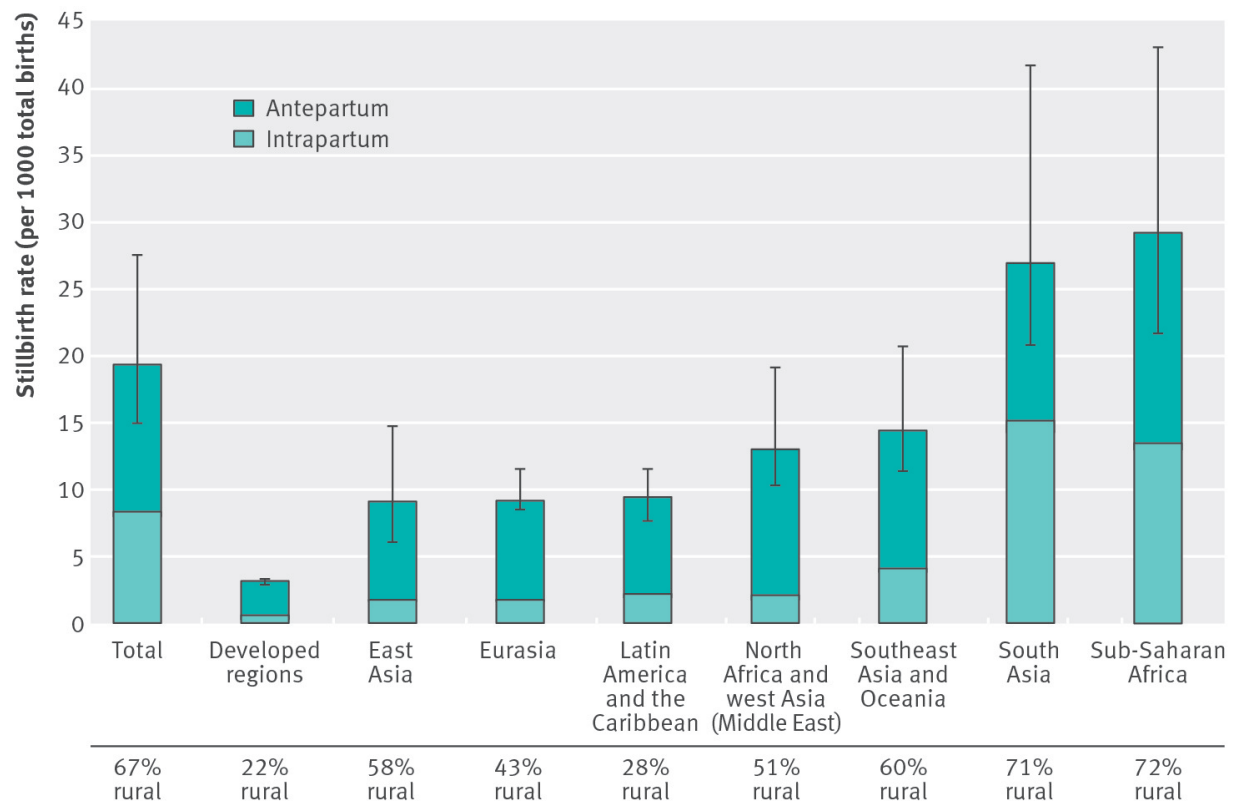

Fig 1 Regional variation in stillbirth rates and the proportion of intrapartum stillbirths using data from 195 countries. $^{2}$ Error bars indicate uncertainty range. 